\title{
On the nature of the facilitation of visual comparisons by lexical membership
}

\author{
LESLIE HENDERSON and JACKIE CHARD \\ The Hatfield Polytechnic, Hatfield, Herts, England
}

\begin{abstract}
Subjects matched meaningful (e.g., FBI) or meaningless (e.g., IBF) letter strings. For "same" decisions meaningfulness was facilitatory, but this effect was slightly reversed for "different" decisions. Unfamiliar lowercase format abolished the meaningfulness effect. Even when stimulus degradation slowed performance, there was no interaction with meaningfulness.
\end{abstract}

A remarkable number of recent studies have been concerned with word superiority effects (WSEs) on tachistoscopic recognition and binary classification reaction time (RT) tasks. One way of justifying this activity is to suppose that these findings converge upon the traditional question of the nature of the effects of familiarity on perception. We may illustrate this question by examining the welfare of one recurrent and provocative view which asserts that the availability of a particular representation in permanent memory facilitates the immediate processing of the visual features which signal that representation.

It is well established that transitional letter redundancy by itself is a sufficient condition for a WSE in threshold (Baron \& Thurston, 1973) and comparison (Barron \& Pittinger, 1974) paradigms. But by "particular" representation we mean to go beyond the use of stored conditional letter probabilities, for it is evident that when orthographic structure is controlled, facilitatory effect of lexical membership remains. There are three types of evidence for this. First, real words are superior to orthographically matched pronounceable nonwords (PNWs) in threshold (Manelis, 1974) and RT (Barron \& Pittinger, 1974) paradigms. Second, lexical membership is facilitatory in the absence of orthographic regularity (FBI vs. IBF; Henderson, 1974). Third, visual comparison speed relates positively to word frequency (Chambers \& Forster, 1975).

The question remains as to whether these lexical effects are upon "the immediate processing of visual features." By this form of words we mean to preclude location of the effect at a verbal recoding stage and at a postencoding stage of comparison or response decision.

At first sight the threshold paradigm seems to speak most directly to the encoding issue. However, it transpires that the superiority of words, at least over single letters, may be peculiarly dependent on the choice of a

These data were gathered while the first author visited Reading University on a Canada Council leave fellowship. We thank Sharon Murphy for data collection and Max Coltheart for programming assistance. Completion of the study was supported by SSRC Grant 3301/1 to the first author. visual mask (Johnson \& McClelland, 1973). Furthermore, response bias explanations of the threshold data have survived in increasingly convoluted form (e.g., Estes, 1975). We turn, therefore, to the RT tasks.

It is logically possible that the WSE in "same". "different" tasks is due to recoding into an economical phonetic code which facilitates the comparison stage. This would explain why pronounceability is facilitatory and, since lexical access speeds phonetic recoding (Forster \& Chambers, 1973), it could even explain superiority of real words over PNWs. However, Baron \& Thurston (1973) have shown that homophones like FORE FOUR are matched as fast as controls like SORE SOUR, so the comparison itself does not seem to be phonetic. Yet it might still be that the availability of an economical phonetic code aids in some fashion the formation of a visual specification of the array.

Other evidence against a comparison stage locus for the WSE was advanced by Krueger (1970) using a letter search task. However, since Krueger's experiment did not include PNWs, it might be that any encoding effect was due solely to transitional letter redundancy rather than lexical access.

We have therefore returned to these issues by combining a WSE which depends upon lexical access (Henderson, 1974) with two manipulations which appear to be purely visual. One consists of stimulus degradation and the other consists of use of lowercase format, which appears to reduce markedly the perceived familiarity of the lexical stimuli (fbi vs FBI).

\section{METHOD}

\section{Apparatus and Materials.}

Stimulus pairs were presented one immediately above the other on a CRT controlled by a PDP-12 computer. Response keys permitted the subject to initiate a trial with the thumb of - the preferred hand and respond "same" with the middle finger and "different" with the other hand. In Experiment I stimulus pairs could be either uppercase or lowercase, with these roughly equated for size and legibility. Stimulus degradation was achieved by illuminating the CRT screen with an external source to provide contrast reduction. In Experiment II all pairs were uppercase and degradation was by means of a random dot mask which was continuously present on the screen.

Nine basic stimuli of proven familiarity were used: FBI, 
Table 1

Mean Correct RT in Experiments I and II as a Function of Meaningfulness, Stimulus Degradation, Type of Response, and (Experiment I Only) Case

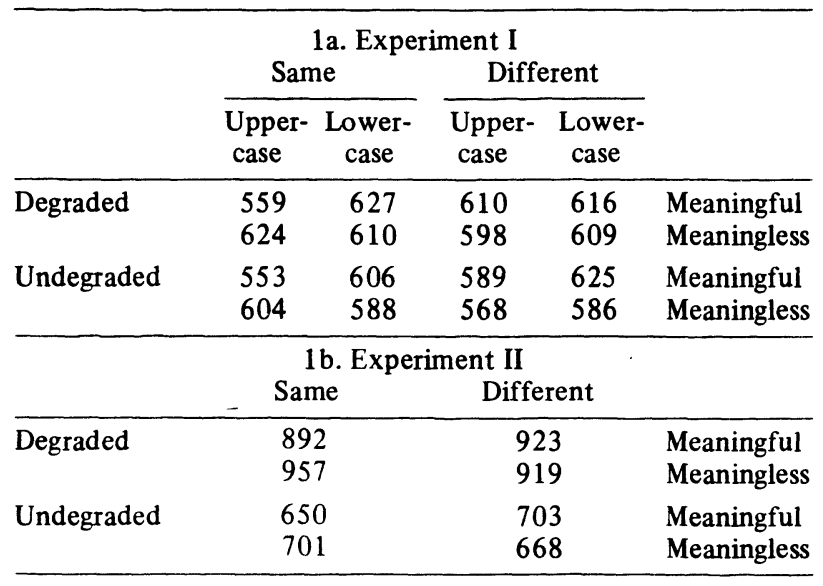

BBC, HMS, ABC, ITV, GSR, LSD, DDT, GPO. Reversing these trigrams produced a set which had been shown to be unfamiliar. The lowercase format had also been shown markedly to reduce rated familiarity of all but the ABC trigram.

High- and low-meaningfulness pairs occurred randomly but with equal frequency. Within this variable, same and different pairs were randomized and equiprobable. Also randomized in Experiment I were two replications of each of the resultant pairs, both in upper and in lowercase format, and in Experiment II four replications, all in uppercase. This yielded a session of 144 trials. Two sessions contained the stimulus degradation factor as a blocked variable, with the order counterbalanced across subjects.

\section{Procedure}

A list of the basic stimuli was shown to the subject, who was informed that neither case nor familiarity would vary within a pair. Performance was self-paced. An initiate button replaced the central fixation point after a 500-msec blank delay with the stimulus pair. Responding replaced the stimulus with the fixation point.

\section{Subjects \\ Fourteen paid volunteers served as subjects, in Experiment I, 16 in Experiment II.}

\section{RESULTS}

\section{Experiment I}

The overall error rate was below $5 \%$ and did not appear to differ between conditions. Mean correct RTs are shown in Table 1a.

An analysis of variance on the "same" RTs revealed significant main effects of case and meaningfulness $(\mathrm{p}<.025)$. A significant interaction between the degradation condition and its counterbalancing order $(p<.005)$ indicated that degradation only interfered when it occurred first. A significant interaction of Case by Meaningfulness $(p<.001)$ clearly showed that the facilitatory effect of meaningfulness held only for uppercase format.

Analysis of the "different" responses revealed a significant effect of case $(\mathrm{p}<.05)$. A reversed effect of meaningfulness approached significance $(p<.10)$. Once again stimulus degradation interacted with order of testing $(\mathrm{p}<.005)$.

\section{Experiment II}

Mean correct RTs are shown in Table 1b. Analysis of "same" responses revealed this time a significant deleterious effect of degradation $(p<.001)$ and a facilitatory effect of meaningfulness $(p<.01)$. None of the interactions approached significance. For "different" responses degradation had a significant effect $(\mathrm{p}<.001)$. The effect of meaningfulness was significantly reversed $(p<.05)$. The interaction of Degradation by Meaningfulness approached significance $(\mathrm{p}<.10)$.

An overall analysis confirmed the significance effect of degradation. While the meaningfulness effect was not significant when "sames" and "differents" were collapsed $(p \approx .10)$, the interaction of Meaningfulness by Response Type was highly significant $(p<.001)$.

\section{DISCUSSION}

\section{Stimulus Degradation and Case Manipulation}

In Experiment I the lack of a main effect of degradation precluded the critical test of the interaction with meaningfulness. The more effective stimulus degradation in Experiment II did slow performance by over $250 \mathrm{msec}$, yet there was little evidence of any interaction with meaningfulness. Additive stage logic suggests, therefore, that these factors reflect different processing stages.

In contrast, the case manipulation was effective. Use of lowercase format, which diminishes the experience of familiarity, abolishes the meaningfulness effect. This refutes any suggestion that phonetic recoding mediates the effect, with an advantage for familiar strings of letter names. Clearly it is visual familiarity which is involved and the visual code which gains lexical access for familiar items is case specific.

Taken together, these two manipulations suggest that, if the familiarity effect is due to encoding facilitation as Henderson (1976) has argued, then it must operate after a separate normalization stage which is affected by degradation.

\section{Meaningfulness and Response Type}

The slight reversal of the meaningfulness effect for "different" decisions confirms the results of Baron (1975) and Besner and Jackson (in press), to whom this suggests a response-decision locus for the effect. This conclusion is difficult to reconcile with two facts. First, the facilitatory effect on "sames" is invariably larger than any deleterious effect on "differents." Second, many studies report no effect on "differents," or even a facilitatory effect which seems to depend on blocking meaningfulness (Henderson, 1974) or using high letter sharing for different pairs (Chambers \& Forster, 1975).

Finally, recent evidence suggests that a comparison stage locus for the familiarity effect is proscribed, since the meaningfulness effect survives even when physical-match instructions compel a "different" response to the same letter strings in differing case (Besner \& Jackson, 1975; Pollatsek, Well, \& Shindler, 1975).

We conclude that the meaningfulness effect is either nomadic or suffers from stage fright.

\section{REFERENCES}

Baron, J. Successive stages in word recognition. In P. M. A. Rabbit \& S. Dornic (Eds.). Attention and performance $V$. London: Academic Press, 1975. 
Baron, J.. \& Thurston, I. An analysis of the word superiority effect. Cognitive Psychology, 1973, 4, 207-228.

Barron. R. W., \& Pittinger. J. B. The effect of orthographic structure and lexical meaning on "same"."different" judgments. Quarterly Journal of Experimental Psychology, 1974, 26. 566-581.

Besner. D.. \& Jackson, A. Same-different judgments with words and nonwords: A word superiority/inferiority effect. Bulletin of the Psychonomic Society, in press.

Chambers, S. M., \& Forster, K. I. Evidence for lexical access in a simultaneous matching task. Memory \& Cognition, 1975, 3. 549-560.

Estes. W. K. The locus of inferential and perceptual processes in letter identification. Journal of Experimental Psychology: General, 1975, 104. 122-145.

Forster, K. I., \& Chambers, S. M. Lexical access and naming time. Journal of Verbal Learning and Verbal Behavior, 1973. 12. 627-635.
Henderson, L. A word superiority effect without orthographic assistance. Quartlerly Journal of Experimental Psychology, 1974. 26, 301-311.

Henderson. L. Word recognition. In N. S. Sutherland (Ed.), Tutorial essays in experimental psychology. Potomac, Md: Erlbaum. 1976

Johnson, J. C., \& MCClelland, J. L. Visual factors in word perception. Perception \& Psychophysics, 1973, 14, 365-370.

KRUEGER, L. E. Search time in a redundant visual display. Journal of Experimental Psychology, 1970, 83, 391-399.

Manelis, L. The effect of meaningfulness in tachistoscopic word perception. Perception \& Psychophysics, 1974, 16, 182-192.

Pollatsek, A., Well, A. D., \& Schindler, R. M. Familiarity affects visual processing of words. Journal of Experimental Psychology: Human Perception and Performance, 1975, 1 , 328-338.

(Received for publication January 26, 1976.) 